\title{
Long-term Survival With Non-functioning Pituitary Carcinoma
}

\author{
-Case Report-
}

\author{
Junji KoYama, Koji IKEDA, Yoshiteru ShOSE, Mitsuru KIMURA, \\ Yoshiro OBORA, and Eiji KOHMURA*
}

\begin{abstract}
Department of Neurosurgery, Nishiwaki Municipal Hospital, Nishiwaki, Hyogo; * Department of Neurosurgery, Kobe University Graduate School of Medicine, Kobe, Hyogo
\end{abstract}

\begin{abstract}
A 35-year-old woman presented with a non-functioning pituitary adenoma manifesting as amenorrhea and impaired visual acuity in $\mathbf{1 9 8 4}$. The tumor was grossly totally resected through a right frontotemporal craniotomy. The patient underwent surgery for three recurrences in the next 5 years. She was treated with gamma knife surgery for the residual tumor in 1994. Follow-up magnetic resonance (MR) imaging revealed a tumor in the right frontal base in 1999, and the left middle fossa in 2002 . Total removal of these tumors was performed. Follow-up MR imaging showed regrowth of the primary pituitary tumor in 2003, which was partially excised. Histological examination of the specimens from the last three surgeries revealed typical pituitary adenoma without malignant transformation. Pituitary carcinomas have a poor prognosis. However, the present patient survived for 22 years from onset and 6 years from the first dural metastasis. Distant lesions should be removed for histological evaluation to assist the subsequent management.
\end{abstract}

Key words: pituitary adenoma, pituitary carcinoma, dural metastasis, MIB-1 index

\section{Introduction}

Pituitary adenoma is usually regarded as a slowgrowing benign tumor, but the long-term incidence of recurrence ranges from $10 \%$ to $35 \% .^{2,3,15)}$ Pituitary adenoma is occasionally aggressive, as histological examination of surgically excised sellar dura frequently shows tumor invasion. ${ }^{11)}$ Pituitary carcinoma is rare with an incidence of less than $1 \%$. The presence of metastatic lesion rather than histological findings is the basis for the diagnosis of pituitary carcinoma. ${ }^{9)}$ Distant metastasis, which is discontinuous from the sella turcica, is commonly recognized as the diagnostic criterion for pituitary carcinoma. ${ }^{13)}$ The overall prognosis of pituitary carcinoma is considered to be exceedingly poor, as two thirds of patients die within 1 year of diagnosis. ${ }^{14}$ Only one patient with adrenocorticotropic hormone-secreting metastatic pituitary carcinoma has survived for more than 20 years. ${ }^{16)}$
We report an interesting case of non-functioning pituitary carcinoma, which showed multiple local recurrences and intracranial metastases during a long and clinically benign course with benign histological findings.

\section{Case Report}

A 35-year-old woman presented at the Nishiwaki Municipal Hospital with amenorrhea, reduced visual acuity, and incomplete bilateral hemianopsia in 1984. Computed tomography showed a pituitary tumor extending to the suprasellar region. The patient underwent gross total excision of the tumor through a right frontotemporal craniotomy. The histological diagnosis was chromophobic adenoma without nuclear proliferation or mitotic figures. The patient needed hormone replacement after surgery. She underwent surgery three more times in the next 5 years because of repeated local recurrences. She

Received December 18, 2006; Accepted July 23, 2007

Author's present address: J. Koyama, M.D., Department of Neurosurgery, Akashi Municipal Hospital, Akashi, Hyogo, Japan. 

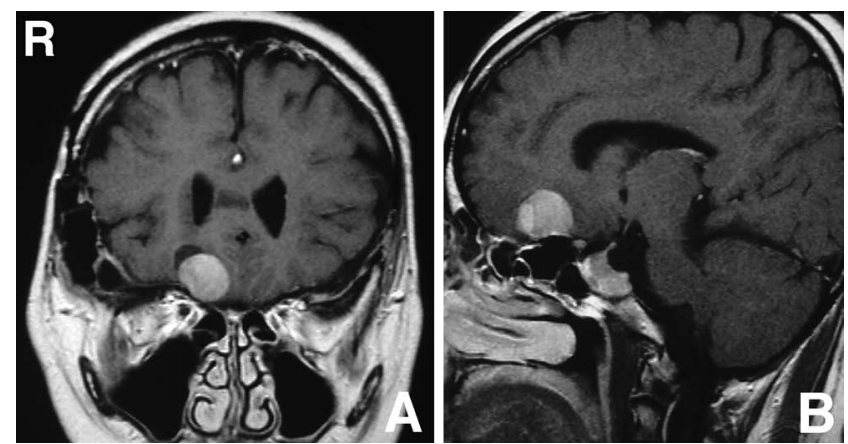

Fig. 1 Preoperative $T_{1}$-weighted magnetic resonance images with gadolinium (A: coronal view, B: sagittal view) showing a homogeneously enhanced mass in the right frontal base.

was treated with gamma knife surgery for the residual tumor in 1994.

Magnetic resonance (MR) imaging revealed a mass lesion in the right frontal base and the patient was readmitted to our institute in October 1999. On admission, MR imaging demonstrated a well-circumscribed mass lesion in the right frontal base, which was attached to the dura. This solid tumor was completely separate from the original pituitary tumor and displayed homogeneous enhancement after gadolinium-diethylenetriaminepenta-acetic acid (Gd-DTPA) administration (Fig. 1). The patient had been receiving hormone replacement therapy since the first surgery, and endocrinological examination demonstrated pan-hypopituitarism. The patient underwent a right frontotemporal craniotomy for total removal of the right frontal lesion, which was the fifth operation, in December 1999. The tumor was attached to the dura of the frontal base. Histological examination of the resected material revealed sinusoidal-type pituitary adenoma (Fig. 2).

MR imaging at the 27-month follow-up examination showed a new lesion in the left middle fossa, which was attached to the dura of the petrous bone. This tumor was also separate from the pituitary tumor and displayed homogeneous enhancement after Gd-DTPA administration (Fig. 3). The patient underwent a left temporal craniotomy, her sixth operation, in which the dural-based tumor was totally excised in April 2002. The histological findings were identical to those of the former tumor and also to the original tumor. The postoperative course was uneventful.

Follow-up MR imaging showed regrowth of the primary pituitary tumor extending into the suprasellar region in February 2003. The tumor was partially

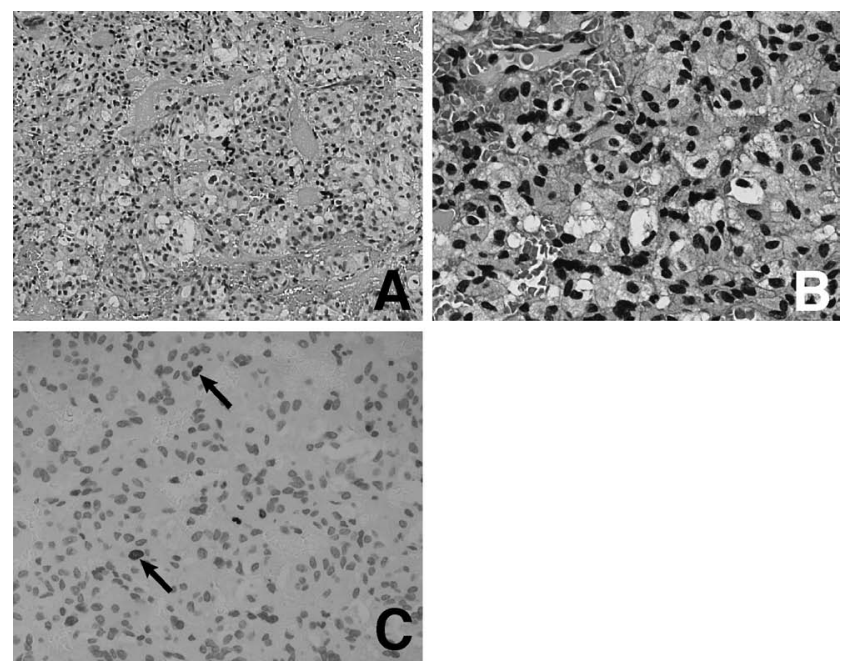

Fig. 2 Photomicrographs of the specimen obtained from the right frontal base tumor in 1999 showing a sinusoidal-type pattern without pleomorphism and mitosis (hematoxylin and eosin stain, original magnification $A$ : $\times 100$, B: $\times 200$ ), and scattered MIB-1-positive cells (arrows) with a MIB-1 labeling index of $1.5 \%$ (C: MIB-1 immunostaining, original magnification $\times \mathbf{2 0 0}$ ).

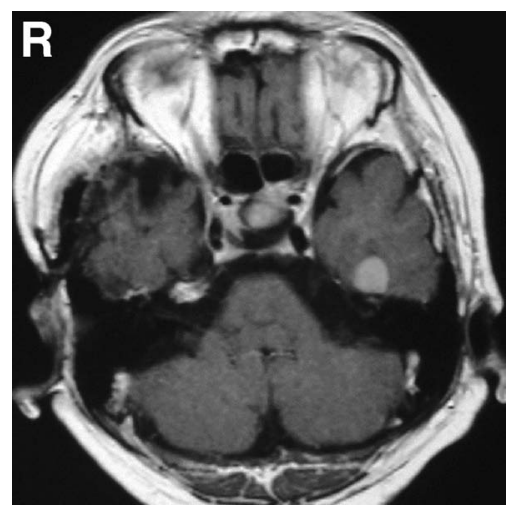

Fig. 3 Axial $T_{1}$-weighted magnetic resonance image with gadolinium before the second surgery showing a homogeneously enhanced mass in the left middle fossa.

excised through a bilateral frontal craniotomy. Postoperative basal hormonal investigation and combined anterior pituitary stimulation test using intravenous injection of regular insulin $(0.1 \mathrm{U} / \mathrm{kg})$, thyroid-stimulating hormone $(500 \mu \mathrm{g})$, and luteinizing hormone-releasing hormone $(100 \mu \mathrm{g})$ showed persistence of hypopituitarism: basal and peak values of growth hormone, luteinizing hormone, follicle-stimulating hormone, prolactin, cortisol, and 


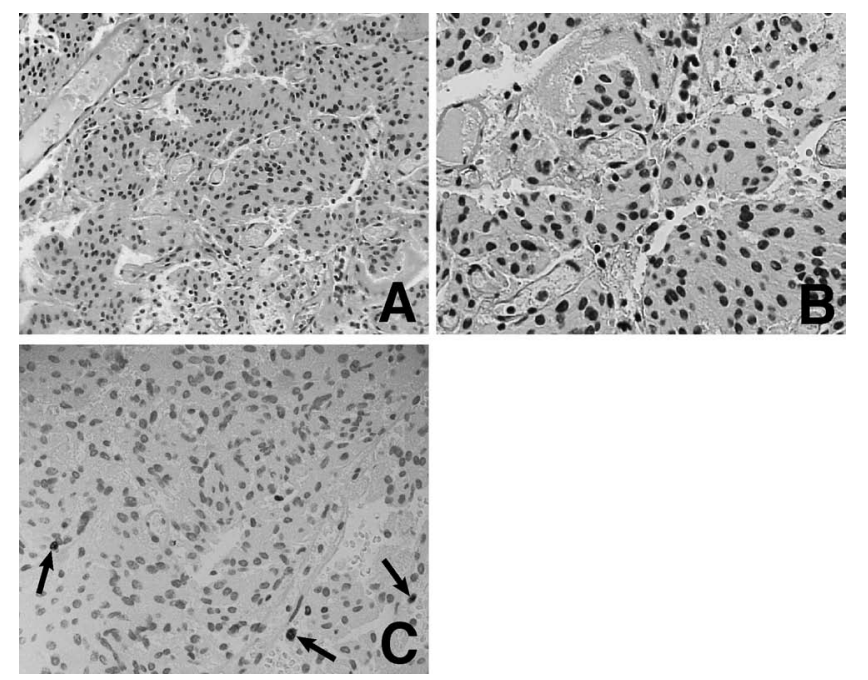

Fig. 4 Photomicrographs of the specimen obtained from the suprasellar lesion at the last operation showing a sinusoidal pattern without pleomorphism and mitosis (hematoxylin and eosin stain, original magnification $A$ : $\times 100$, B: $\times 200$ ), and scattered MIB-1-positive cells (arrows) with a MIB-1 labeling index of $2.2 \%$ (C: MIB-1 immunostaining, original magnification $\times \mathbf{2 0 0}$ ).

adrenocorticotropic hormone were $0.04 \mathrm{ng} / \mathrm{ml}$ and $0.28 \mathrm{ng} / \mathrm{ml}$ (normal: $0.28-1.64$ ), $<0.10 \mathrm{mIU} / \mathrm{ml}$ and $<0.10 \mathrm{mIU} / \mathrm{ml}, \quad 0.12 \mathrm{mIU} / \mathrm{ml}$ and $\quad 0.15 \mathrm{mIU} / \mathrm{ml}$, $<0.60 \mathrm{ng} / \mathrm{ml}$ and $<0.60 \mathrm{ng} / \mathrm{ml}, 1.1 \mu \mathrm{g} / \mathrm{dl}$ and 2.6 $\mu \mathrm{g} / \mathrm{dl}$ (normal: $4.0-18.3$ ), and $7.4 \mathrm{pg} / \mathrm{ml}$ and 73.9 $\mathrm{pg} / \mathrm{ml}$ (normal: 7.4-55.7), respectively. Three months after discharge, no clinical deterioration was noted.

Histological examination of the tissues resected in 1999, 2002, and 2003 revealed a sinusoidal pattern, consistent with pituitary adenoma and metastasis from pituitary adenoma (Figs. 2A, B and 4A, B). The tumor cells showed no mitoses or nuclear atypism and were negative for immunohistochemical staining for p53. The MIB-1 staining index increased slightly during the course from $1.5 \%$ in 1999 to $2.2 \%$ in 2003 (Figs. 2C and 4C).

\section{Discussion}

Primary pituitary lesion is often found to be a functioning adenoma with invasive growth. ${ }^{16)}$ Both p53 protein expression and proliferative potential measured by antibody to MIB-1 or proliferating cell nuclear antigen may provide predictors of recurrence or malignant transformation of pituitary tumor. ${ }^{1,8,12,19,20)}$ Recurrent pituitary tumors, which are usually functioning adenomas, have higher positivity to MIB-1 and p53. ${ }^{12)}$ Pituitary carcinoma should also be defined by the following histological features: elevated mitotic index and Ki-67 labeling index greater than $3 \%$, and extensive nuclear staining for p53 immunoreactivity. ${ }^{4)}$ It is unique that the MIB-1 index in this dural implantation of pituitary carcinoma was less than $3 \%$.

Pituitary carcinoma has three forms. ${ }^{18)}$ In the first, the primary pituitary tumor is already malignant at onset, and may invade the surrounding structures or spread to other organs. In the second, the primary tumor shows originally benign histology but malignant transformation is recognized at metastasis. ${ }^{6,17)}$ In the third, the histology remains benign even if metastasis occurs. Our case corresponds to the third form, of which there have been four previous cases. ${ }^{8,10,13,18)}$ However, our patient has survived for a long time (22 years from onset, 6 years from the first dural metastasis) without histological malignant transformation. Therefore, our case has followed an unusual clinical course for pituitary carcinoma.

There are three mechanisms of metastasis from pituitary adenoma. Drop metastasis occurs in the surgical tract, which did not occur in our case because the dural metastases occurred in regions unrelated to the surgical pathway. ${ }^{5,7)}$ Metastasis via the cerebrospinal fluid pathways occurs mostly after a craniotomy procedure, so may be related to our case but is unlikely, because there were not many metastatic lesions and the locations did not coincide. The third mechanism is blood-borne metastasis. Microscopic dural invasion was recognized in $45.5 \%$ of patients after sellar dura excision at transsphenoidal surgery for pituitary adenoma. ${ }^{11)}$ In our case, the primary pituitary adenoma recurred repeatedly, but we did not search the sellar dura. Our case was similar to a previous case of pituitary adenoma with multiple dural metastases. ${ }^{8)}$ Therefore, we suspect that the primary pituitary adenoma invaded the sellar dura and hematogeneously metastasized to other dural locations. ${ }^{8}$ On the other hand, the previous and present cases show some differences in the numbers of dural metastases, progression of metastatic disease, and outcome. In our case, there were only two dural metastatic lesions which were small and well-circumscribed mass lesions, without symptoms. Therefore, our case was more "benign" pituitary carcinoma than in the previous case. ${ }^{8)}$ Other factors such as surgical- or radiation-induced alterations of the characteristics of the primary tumor may have been important in our patient.

Although the prognosis for pituitary carcinoma is considered very poor, our patient has survived for 
22 years from onset and 6 years from the first dural metastasis. We suggest that surgical resection of the metastatic tumor could be beneficial for identifying the cellular proliferative potential of pituitary carcinoma with atypical presentation, such as non-functioning or sporadic metastatic lesion, which would assist the subsequent management.

\section{References}

1) Buckley N, Bates AS, Broome J, Strange R, Perrett C, Burke C, Clayton R: p53 protein accumulates in Cushing's adenomas and invasive non functional adenomas. J Clin Endocrinol Metab 79: 1513-1516, 1994

2) Ciric I, Mikhael M, Stafford T, Lawson L, Garces R: Transsphenoidal microsurgery of pituitary macroadenomas with long-term follow-up results. J Neurosurg 59: 395-401, 1983

3) Ebersold MJ, Quast LM, Laws ER Jr, Scheithauer B, Randall RV: Long-term results in transsphenoidal removal of nonfunctioning pituitary adenomas. J Neurosurg 64: 713-719, 1986

4) Figarella-Branger D, Trouillas J: The new WHO classification of human pituitary tumors: comments. Acta Neuropathol (Berl) 111: 71-72, 2006

5) Gollard R, Kosty M, Cheney C, Copeland B, Bordin G: Prolactin-secreting pituitary carcinoma with implants in the cheek pouch and metastases to the ovaries: A case report and literature review. Cancer 76: 1814-1820, 1995

6) Hosaka N, Kitajiri S, Hiraumi H, Nogaki H, Toki J, Yang G, Hisha H, Ikehara S: Ectopic pituitary adenoma with malignant transformation. Am J Surg Pathol 26: 1078-1082, 2002

7) Koetsveld AC, Bartels RH, Wijnberg DS, Hermus AR, Lammens M: Drop metastasis from pituitary adenoma. Case illustration. J Neurosurg 95: 719, 2001

8) Kumar K, Kelly M: Benign pituitary adenoma with multiple dural metastases: A case report. Surg Neurol 54: 380-383, 2000

9) Lubke D, Saeger W: Carcinomas of the pituitary: Definition and review of the literature. Gen Diagn Pathol 141: 81-92, 1995

10) Madonick MJ, Rubinstein LJ, Dasco MR, Ribner H: Chromophobe adenoma of pituitary gland with subarachnoid metastases. Neurology 13: 836-840, 1963

11) Meij BP, Lopes MB, Ellegala DB, Alden TD, Laws ER Jr: The long-term significance of microscopic dural invasion in 354 patients with adenomas treated with transsphenoidal surgery. J Neurosurg 96: 195-208, 2002

12) Miyagami M, Nakamura S: [Significance of p53 protein expression and proliferative potential with MIB-1 on tumor recurrence of pituitary adenomas]. No To Shinkei 50: 27-32, 1998 (Jpn, with Eng abstract)

13) O’Brien DP, Phillips JP, Rawluk DR, Farrell MA: Intracranial metastases from pituitary adenoma. Br J Neurosurg 9: 211-218, 1995

14) Pernicone PJ, Scheithauer BW, Sebo TJ, Kovacs KT, Horvath E, Young WF Jr, Lloyd RV, Davis DH, Guthrie BL, Schoene WC: Pituitary carcinoma: A clinicopathologic study of 15 cases. Cancer 79: 804-812, 1997

15) Rauhut F, Clar HE, Bamberg M, Benker G, Grote W: Diagnostic criteria in pituitary tumour recurrencecombined modality of surgery and radiotherapy. Acta Neurochir (Wien) 80: 73-78, 1986

16) Scheithauer BW, Kurtkaya-Yapicier O, Kovacs KT, Young WF Jr, Lloyd RV: Pituitary carcinoma: A clinicopathological review. Neurosurgery 56: 1066-1074, 2005

17) Tanaka Y, Tsuda M, Sato M, Kanno H, Tokoro K, Yamamoto I, Kimura S, Kitamura H: [CSF dissemination of a pituitary adenoma: A case report]. No Shinkei Geka Journal 5: 391-397, 1996 (Jpn, with Eng abstract)

18) Taylor WS, Uttley D, Wilkins PR: Multiple dural based metastasis from pituitary adenoma. J Neurosurg 81: 624-626, 1994

19) Thapar K, Kovacs K, Scheithauer BW, Stefaneanu L, Horvath E, Pernicone PJ, Murray D, Laws ER Jr: Proliferative activity and invasiveness among pituitary adenomas and carcinomas: An analysis using the MIB-1 antibody. Neurosurgery 38: 99-106, 1996

20) Thapar K, Scheithauer BW, Kovacs K, Pernicone PJ, Laws ER Jr: p53 expression in pituitary adenomas and carcinomas: Correlation with invasiveness and tumor growth fractions. Neurosurgery 38: 765-770, 1996

Address reprint requests to: Junji Koyama, M.D., Department of Neurosurgery, Akashi Municipal Hospital, 1-33 Takasho-machi, Akashi, Hyogo 673-8501, Japan.

e-mail: jkoyama@med.kobe-u.ac.jp 